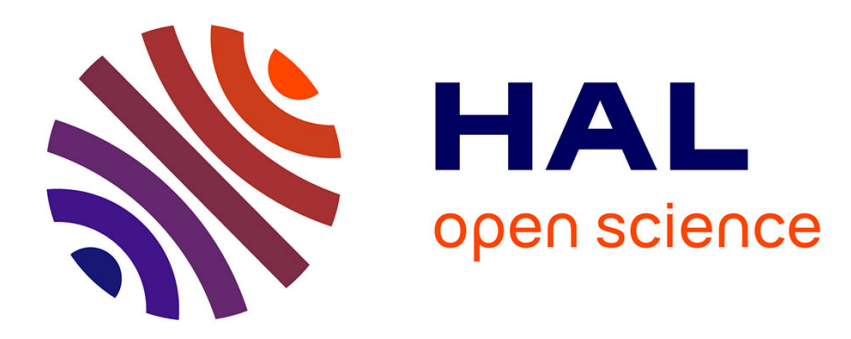

\title{
Thermal dilatation in functional tolerancing
}

Sami Benichou, Bernard Anselmetti

\section{To cite this version:}

Sami Benichou, Bernard Anselmetti. Thermal dilatation in functional tolerancing. Mechanism and Machine Theory, 2011, 10.1016/j.mechmachtheory.2011.06.009 . hal-01239309

\section{HAL Id: hal-01239309 https://hal.science/hal-01239309}

Submitted on 7 Dec 2015

HAL is a multi-disciplinary open access archive for the deposit and dissemination of scientific research documents, whether they are published or not. The documents may come from teaching and research institutions in France or abroad, or from public or private research centers.
L'archive ouverte pluridisciplinaire HAL, est destinée au dépôt et à la diffusion de documents scientifiques de niveau recherche, publiés ou non, émanant des établissements d'enseignement et de recherche français ou étrangers, des laboratoires publics ou privés. 


\title{
Thermal dilatation in functional tolerancing
}

\author{
Sami Benichou ${ }^{(1)}$, Bernard Anselmetti ${ }^{(1)(2)}$ \\ ${ }^{(1)}$ LURPA, ENS Cachan, 61, Avenue du Président Wilson, 94235 Cachan Cedex, France \\ (2) Univ Paris-Sud 11, IUT Cachan, 9, avenue de la division Leclerc, 94230 Cachan, France \\ Corresponding author: sami.benichou@lurpa.ens-cachan.fr
}

\begin{abstract}
Functional tolerancing is classically based onto dimension chains to respect functional requirements. Tolerance synthesis deals to optimize dimensions in order to maximize tolerances. This method is classically used taking into account only geometrical defaults. For mechanisms concerned with notable variation of temperature in different stages of functioning, thermal expansion needs to be studied. This expansion has a direct impact onto clearances and dimensions of the mechanism. In order to deal with this thermal problematic, the purpose of this paper is to consider thermal expansion of parts integrated within functional tolerancing. In particular, this paper will compare the effects of tolerancing, thermal expansion and uncertainties of temperature in order to know if the uncertainties of temperature must be included in the tolerance chain or can be neglected as second order. A basic experimental mechanism is used to show this method and the differences between the two approaches.
\end{abstract}

\section{Keywords:}

Functional dimensioning, functional tolerancing, thermal expansion, integrated design

\section{Introduction}

Functional tolerancing deals with assembly and performance of a mechanism. The purpose of tolerance synthesis is to determine all dimensions and tolerances of a mechanism in order to assure assembly and accuracy of the mechanism. This involves among other things an evaluation of clearances. Usually, this analysis is performed only onto geometric defaults.

While a mechanism is running, the intern temperature of each part changes. Those temperature variations are different from a part to another and may not be uniform when the mechanism is on a steady stage. Moreover, parts are made with various materials. So there are various coefficients of thermal expansion and lengths variations are different. Due to all this, when temperature increases, clearances and dimensions changes. Thus, dimension chains resultants are impacted. To analyze effects of temperature variations on mechanisms, finite elements analyses are classically performed. Those analyses are performed onto nominal 
CAD models and give displacement of all points of parts. Thus, designer can determine the temperature effect onto functional requirement.

On one side, tolerances and clearances effects onto requirements are studied at ambient temperature. On the other side, temperature effects onto requirements are studied considering perfect connections without clearances. To combine those two elements, the temperature effect is added into the resultant of the specification chain.

The problem of this method is that the clearances are dependent on temperature. Moreover, the kind of fitting shapes are not perfect anymore while thermal expansion is taken into account if temperature is not uniform.

All this implies the integration of thermal expansion on worst case in the requirements.

The purpose of this paper is to present a method to take in account thermal expansion into a classical tolerance synthesis, using the analysis line approach.

The present paper starts with a state of art of functional tolerancing and dimensioning. After that, a presentation of the experimental mechanism and its classical functional tolerancing is produced. Next, the explanation of the integration of thermal dilatation onto functional tolerancing and its application on the mechanism is shown. Then an example compares result without thermal effect, with nominal thermal effect and with nominal thermal effect and uncertainties. An approach of how to integrate finite elements in the method is proposed in order to study complex temperature effects. At last, a conclusion and future prospects are performed.

\section{State of art}

Tolerance synthesis leads to define limits of geometric defaults of parts. Those limits are defined with specification chains which can be identified by various methods based on worst case effects [1], statistical approach [2, 3], distributed models [4], or vector loop [5]. Then, values of tolerances could be calculated by several methods as uniform or iso-capability [6]. The proposed method is based on analysis line approach and the notion of displacement of contact points into a direction developed in [7]. Moreover, to integrate finite elements results, it is preferable to computerize the method. For that, the proposed method is based on CLIC (French acronym for "localization tolerancing with contact influence") explained in [8].

Temperature variations of a mechanism lead to thermal expansion of parts. Those expansions can be calculated by some software as ANSYS Mechanical, I-DEAS TMG, NASTRAN or SIMULIA.

The integration of tolerance analyses with other aspects of design and calculation increases. There are many works about the interactions of global deformations and tolerances $[9,10]$. However there are not many researches on the interaction between thermal expansion and tolerancing. Some of those as [11] try to reduce thermal influence without acting onto tolerances. They look over the tolerances and with this they analyze initial boundaries to apply on the system to increase the performance. Nonetheless, other researches as [12] are in quest of changing tolerances of the mechanism to control the thermal influence. This last point of view is considered in this paper. 


\section{The demonstrator mechanism}

\subsection{Description of the mechanism and hypotheses}

The experimental mechanism can be an elementary representation of an electric motor (Fig.1). It is composed by four parts: the shaft $(\mathrm{S})$, the housing $(\mathrm{H})$, the bearing $(\mathrm{B})$ and the support. The shaft is mounted with clearance on the housing and the bearing. Those two last parts are screwed onto the support. A key is fitted in a slot of the housing. Both key and housing are mounted with clearance onto the support. The bearing is positioned in the same way.

$\mathrm{P}$ is the point of the real axis of the left cylinder of the shaft on left face (Fig.1). The functional requirement to check is the localization of point $\mathrm{P}$ from the datum plane $\mathrm{R}$, with a theoretical dimension of $L_{F}$ and with a tolerance of $t_{P}$. This tolerance zone should be respected for each thermal stage of the mechanism.

The purpose of this paper is to study the influences of deviations and clearances onto the localization of $\mathrm{P}$. Then the influences onto $\mathrm{P}$ position due to a temperature variation onto the housing and the bearing will be shown.

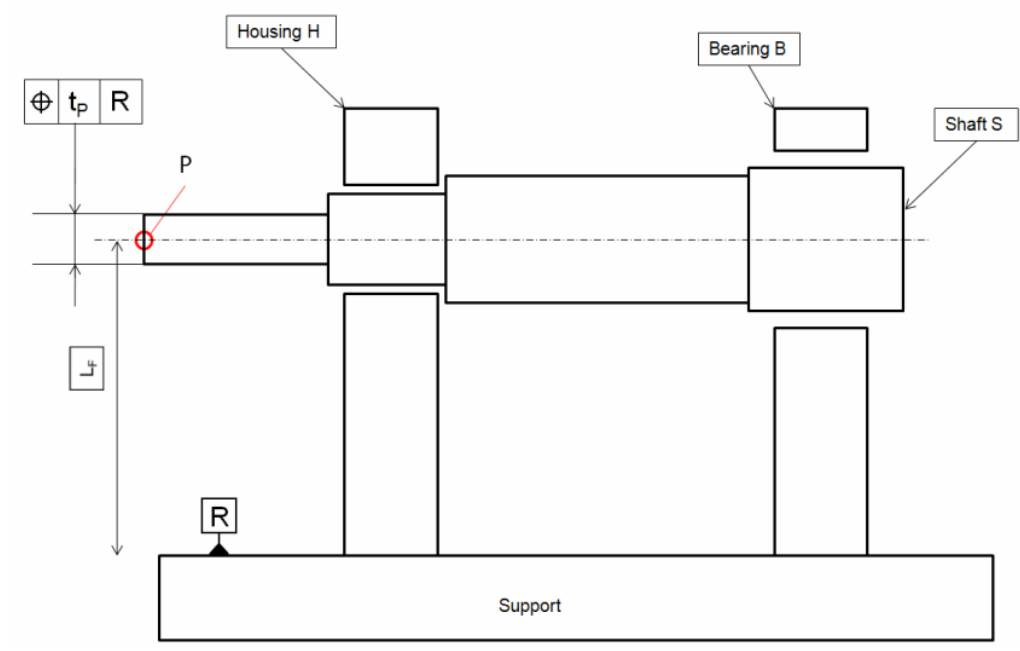

Figure 1: Functional requirement

The real distance between $\mathrm{P}$ and $\mathrm{R}$ is noted $\mathrm{Y}$. The requirement can be expressed with two conditions:

$$
\left\{\begin{array}{l}
Y_{\max } \leq L_{F}+\frac{t_{P}}{2} \\
Y_{\min } \leq L_{F}-\frac{t_{P}}{2}
\end{array}\right.
$$

To limit the study, the support will be considered as a perfect part. Consequently, the datum planes of both the housing and the bearing are merged with plane R. 


\subsection{Tolerancing of the mechanism}

The displacement of the point $\mathrm{P}$ may be calculated in worst case considering the shaft, the housing and the bearing on least material condition [7].

The ISO tolerancing (Fig.2) ensures the assembling of parts and limits the deviation of P.

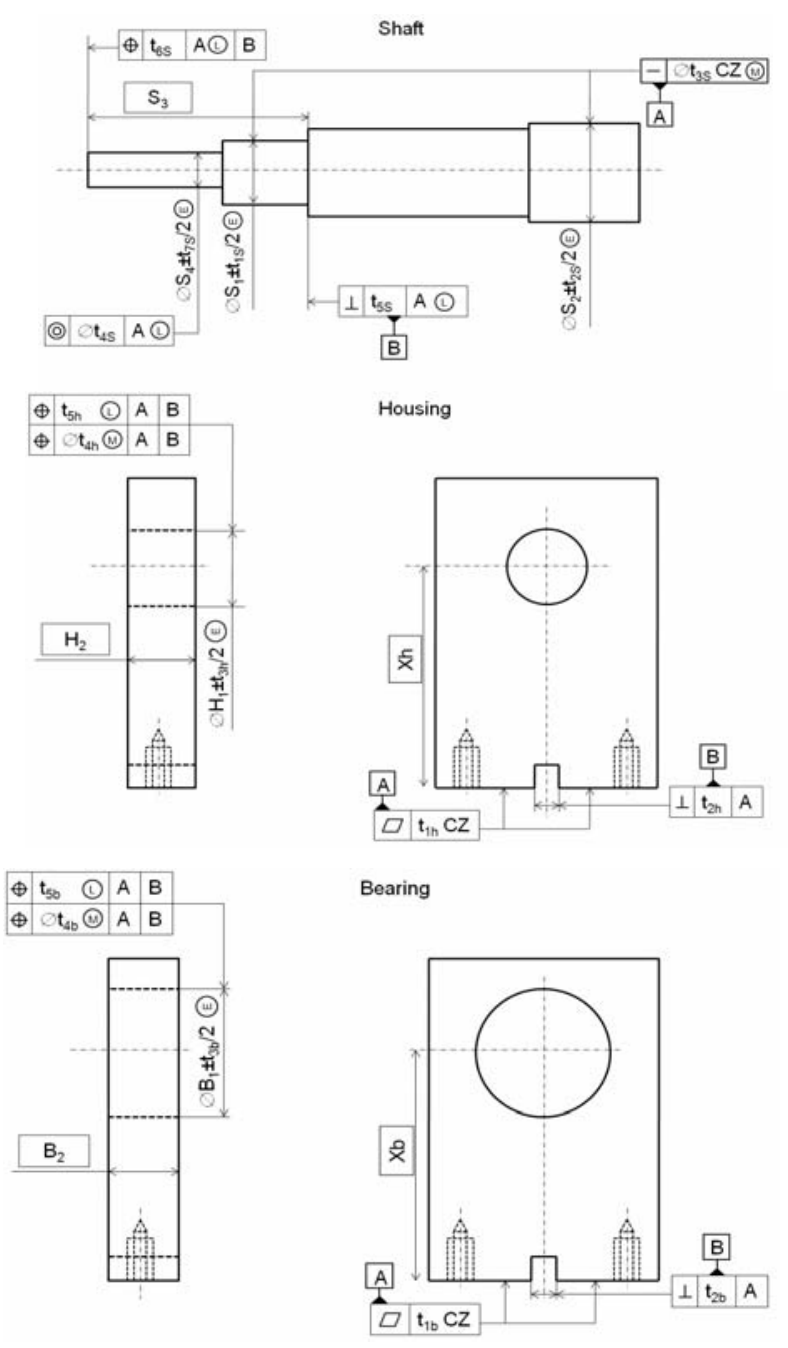

Figure 2: ISO Tolerancing of the mechanism

To get the distance $\mathrm{L}_{\mathrm{F}}$ between the plane $\mathrm{R}$ and the point $\mathrm{P}$, taking into account the dilatation effects, it is needed to optimize $X_{h}$ and $X_{b}$. The coaxiality of these two holes at ambient temperature needs $X_{h}=X_{b}=X$. The nominal axis of the holes is at a distance of $X$ from the datum R (Fig.3).

The $\mathbf{f}$ direction is normal to plane $R$. the deviation of point $P$ in direction $\mathbf{f}$ is noted $d(P, \mathbf{f})$. Point $\mathrm{P}$ is the nominal point on the nominal axis of the holes. $\mathrm{P}^{\prime}$ is the real point in the worst case. $\mathrm{d}(\mathrm{P}, \mathbf{f})=(\mathbf{P P}$.f $)$. The purpose of this work is to determine the worst case deviation onto the point $\mathrm{P}$ in the vertical direction $\mathbf{f}$ giving the maximal value of $\mathrm{Y}$. 


$$
Y=X+d(P, \mathbf{f})
$$

On the same way, the deviation of $\mathrm{P}$ in $-\mathbf{f}$ direction corresponding to the minimal value of $\mathrm{Y}$ is noted $\mathrm{d}(\mathrm{P}, \mathbf{- \mathbf { f }})$.

\subsection{Influence of the coaxiality of the shaft}

The maximal deviation of point $\mathrm{P}$ is reached when the holes and the shaft are at least material condition and when the shaft is inclined in the holes according Figure 3. In this configuration, the two cylinders of the shaft are perfectly coaxial and define datum axis A of the shaft.

Figure 2 depicts the tolerancing of the shaft and in particular the coaxiality $t_{4 S}$ of the left cylinder.

The shaft could rotate around its axis. So the eccentricity of the left cylinder of the shaft will move the point $\mathrm{P}$ of a maximal value of $\mathrm{t}_{4 \mathrm{~S}} / 2$ from the shaft axis $\mathrm{A}$ (Fig.3).

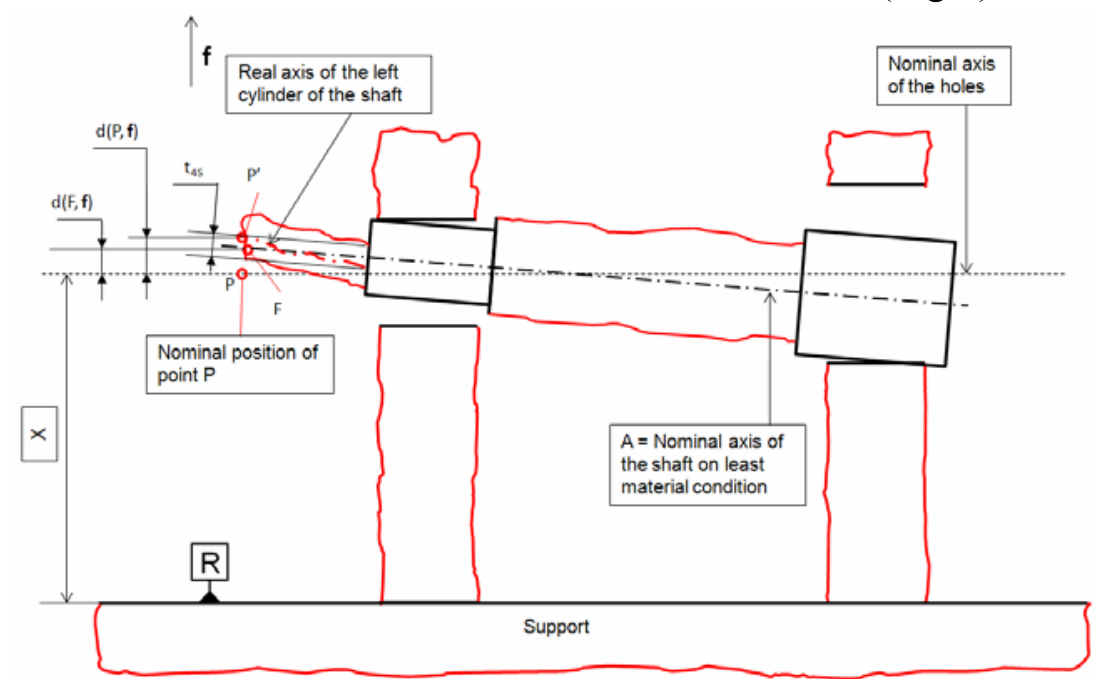

Figure 3: Position of points $P$ and $F$

$\mathrm{F}$ is the point of the shaft axis A on the left surface.

So:

$$
\left\{\begin{array}{l}
d(P, f)=d(F, f)+\frac{t_{4 S}}{2} \\
d(P,-f)=d(F,-f)+\frac{t_{4 S}}{2}
\end{array}\right.
$$

\subsection{Geometric variations at ambient temperature}


While applying a small force onto point $\mathrm{F}$ in $\mathbf{f}$ direction, the shaft goes to be in contact with points $\mathrm{P}_{\mathrm{h}}$ and $\mathrm{P}_{\mathrm{b}}$ (Fig.4). In $\mathrm{P}_{\mathrm{h}}$, the contact direction is $\mathbf{f}_{\mathbf{1}}=\mathbf{f}$. In $\mathrm{P}_{\mathrm{b}}$, the contact direction is $\mathbf{f}_{\mathbf{2}}=$ -f.

Characteristic lengths are $\mathrm{L}_{\mathrm{w}}$ and $\mathrm{L}_{\mathrm{p}}$. The displacements of $\mathrm{P}_{\mathrm{h}}$ and $\mathrm{P}_{\mathrm{b}}$ are maximal if the housing, the bearing and the shaft are at least material conditions.

Considering these cases, Figure 4 presents the shaft as a perfect part with minimum diameters. Housing and bearing are considered at virtual least material limits.

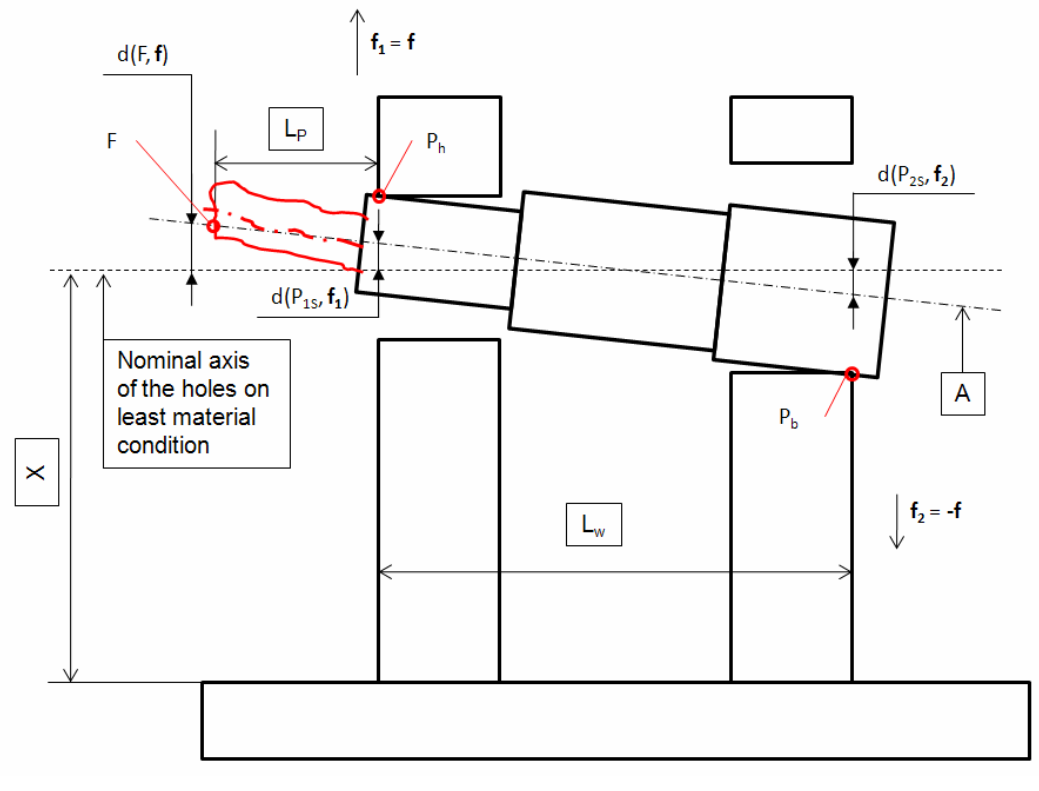

Figure 4: Analysis directions

The biggest displacement of $\mathrm{P}_{1 \mathrm{~S}}$ will occur when the clearance between parts will be maximal and the position deviation of the hole of the housing will also be maximal in one particular direction. This displacement may be calculated by subtracting the diameter of the two parts at least material condition.

$$
\begin{aligned}
& d\left(P_{1 S}, f_{1}\right)=\frac{\left(H_{1}-S_{1}\right)+\left(\frac{t_{1 S}}{2}+\frac{t_{3 h}}{2}+t_{5 h}\right)}{2} \\
& d\left(P_{2 S}, f_{1}\right)=\frac{\left(B_{1}-S_{2}\right)+\left(\frac{t_{2 S}}{2}+\frac{t_{3 b}}{2}+t_{5 b}\right)}{2}
\end{aligned}
$$

The displacement of $\mathrm{F}$ from the nominal axis could be calculated considering the triangles created by $d(F, \mathbf{f}), d\left(P_{1 S}, \mathbf{f}_{1}\right), d\left(P_{2 S}, \mathbf{f}_{2}\right)$, the nominal axis of the holes and the nominal axis of the shaft (Fig.4).

$$
d(F, f)=K_{H} \times d\left(P_{1 S}, f_{1}\right)+K_{B} \times d\left(P_{2 S}, f_{2}\right)
$$

With: 


$$
\left\{\begin{array} { l l } 
{ K _ { H } = \frac { L _ { P } + L _ { w } } { L _ { w } } } & { ( 7 ) } \\
{ K _ { B } = \frac { L _ { P } } { L _ { w } } } & { }
\end{array} \quad \left\{\begin{array}{l}
f_{1}=f \\
f_{2}=-f
\end{array}\right.\right.
$$

The maximal deviation of $\mathrm{P}$ at ambient temperature $\mathrm{Y}_{\max }{ }^{a}$ has to respect:

$$
Y_{\max }^{a}=X+d(P, f)=X+\frac{t_{4 S}}{2}+K_{H} \times d\left(P_{1 S}, f_{1}\right)+K_{B} \times d\left(P_{2 S}, f_{2}\right) \leq L_{F}+\frac{t_{P}}{2}
$$

With the same way, the minimal displacement of $\mathrm{P}$ at ambient temperature $\mathrm{Y}_{\min }{ }^{a}$ which is the maximal displacement of $\mathrm{P}$ in $\mathbf{- f}$ direction has to respect:

$$
Y_{\min }^{a}=X-d(P,-f)=X-\frac{t_{4 S}}{2}-K_{H} \times d\left(P_{1 S},-f_{1}\right)-K_{B} \times d\left(P_{2 S},-f_{2}\right) \geq L_{F}-\frac{t_{P}}{2}
$$

The tolerances are maximal if:

$$
\left\{\begin{array}{l}
Y_{\max }^{a}=L_{F}+\frac{t_{P}}{2} \\
Y_{\min }^{a}=L_{F}-\frac{t_{P}}{2}
\end{array}\right.
$$

For this mechanism, the clearances and the tolerances are symmetric on nominal. Thus:

$$
\left\{\begin{array}{l}
d\left(P_{1 S}, f\right)=d\left(P_{1 S},-f\right) \\
d\left(P_{2 S}, f\right)=d\left(P_{2 S},-f\right)
\end{array}\right.
$$

The sum of equations 11 taking into account 9,10 and 12 gives the value of $X$.

$$
X=\frac{Y_{\max }+Y_{\min }}{2}=L_{F}
$$

The difference gives the limits of the tolerance values.

$$
\frac{t_{4 S}}{2}+K_{H} \times d\left(P_{1 S}, f_{1}\right)+K_{B} \times d\left(P_{2 S}, f_{2}\right)=\frac{Y_{\max }-Y_{\min }}{2}=\frac{t_{P}}{2}
$$

The mechanism will respect the requirement while:

$$
\left\{\begin{array}{l}
X=L_{F} \\
t_{4 S}+K_{H} \times\left(H_{1}-S_{1}+\frac{t_{1 S}}{2}+\frac{t_{3 h}}{2}+t_{5 S}\right)+K_{B} \times\left(B_{1}-S_{2}+\frac{t_{2 S}}{2}+\frac{t_{3 b}}{2}+t_{5 b}\right)=t_{P}
\end{array}\right.
$$

This relation lets to distribute tolerances for example with iso-capability method [8]. 


\section{Tolerance taking into account the thermal expansion}

\subsection{Thermal model}

When a mechanism runs, the temperature increases, the shape and dimensions of each part change. The purpose of this section is to take into account temperature variations onto the housing and the bearing. The support and the shaft are considered without thermal deviation.

To simplify this complex thermal problem, four hypotheses are proposed:

- The housing and the bearing could have been made into different materials. But they are supposed homogeneous in all directions.

- The temperature increases from ambient temperature to maximal temperature.

- The temperature is uniform in each part.

- The temperature variation may be different for the housing and the bearing.

Definition drawing (Fig.2) depicts parts on reference temperature $\left(\theta_{0}=20^{\circ} \mathrm{C}\right)$ used in metrology. All theoretical dimensions are defined for this reference temperature. In functioning, the expansion on parts depends on the difference between the real temperature $\theta_{\mathrm{T}}$ and this reference temperature $\theta_{0}$. Moreover, there could be uncertainties onto temperature.

So the temperature variation of a part $\mathrm{j}$ on stage $\mathrm{T}$ will be written as follow:

$$
\Delta \Theta_{j / T}=\left(\theta_{j / T}-\theta_{0}\right) \pm \frac{\Delta \theta_{j / T}}{2}
$$

With:

$\Delta \Theta_{\mathrm{j} / \mathrm{T}}$ temperature variation of part $\mathrm{j}$ on stage $\mathrm{T}$

$\theta_{0}$ reference temperature $\left(20^{\circ} \mathrm{C}\right)$

$\theta_{\mathrm{j} / \mathrm{T}}$ nominal temperature of part $\mathrm{j}$ on stage $\mathrm{T}$

$\Delta \theta_{\mathrm{j} / \mathrm{T}}$ uncertainty on temperature of the part $\mathrm{j}$ on stage $\mathrm{T}$

Figure 5 depicts a basic thermal cycle where horizontal axis represents the time. For example, the thermal model of the housing lets to define the nominal curve represented by triangles. However, the uncertainties of the model let to create two curves represented by squares and points.

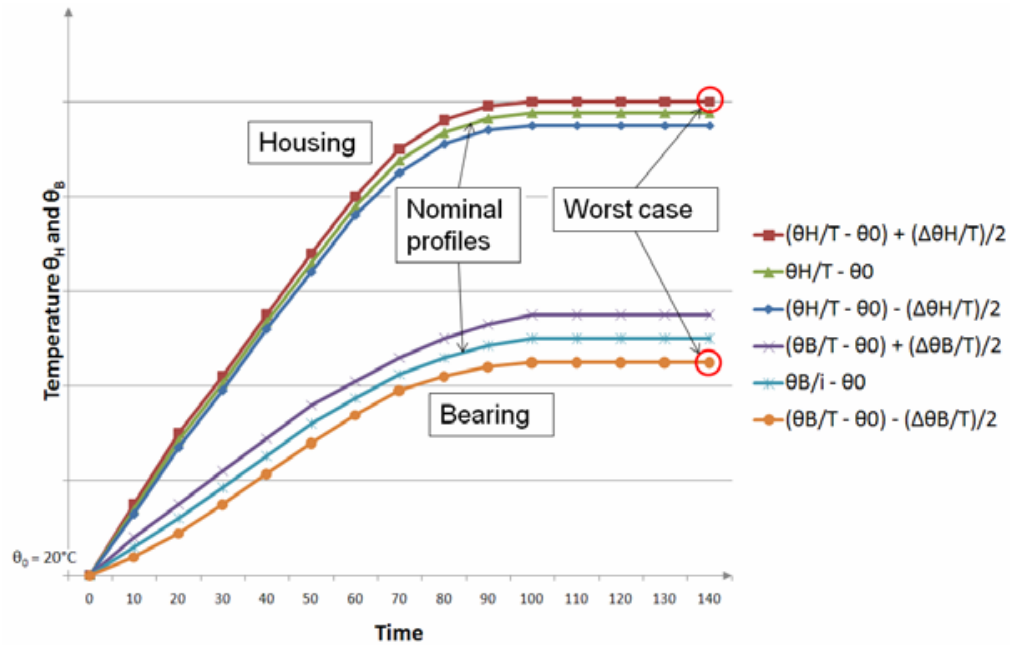

Figure 5 : Temperature profiles while the mechanism is running 
For the experimental mechanism, stages are defined by the time.

The requirement must be verified for all stages and all combinations of limits according to uncertainties. In general cases, the thermal cycle is more complex but in this particular case, the worst case in $\mathbf{f}$ direction is easily found and illustrated in Fig. 5 by the circle corresponding to the maximal limit on the housing and the minimal limit on the bearing.

In this case, it is impossible to consider $\theta_{\mathrm{H}}$ at maximal value and $\theta_{\mathrm{B}}$ at ambient temperature because this configuration does not appear.

\subsection{Influence of temperature}

To connect tolerancing method and thermal models, the proposed approach is based on three ideas:

- The tolerancing model determines the contact points between parts on the worst case.

- The requirement conditions are expressed as a linear function of deviations on these contacts points (see for example equations 9 and 10).

- The deviation of one contact point is the sum of deviation due to tolerances and of displacement due to dilatation on this point.

The displacement of those points might be known for every kind of temperature profile, even complex ones, using finite elements.

The simplifying hypotheses let to obtain the displacement of point considering datum plane $\mathrm{R}$ as fixed plane $\left(\alpha_{H}\right.$ is the coefficient of thermal expansion of the material of the housing $\left.H\right)$.

$$
\begin{aligned}
& d\left(P h, f_{1}\right)=\left(X+\frac{H_{1}}{2}\right) \alpha_{H} \times \Delta \Theta_{H / T} \\
& d\left(P b, f_{2}\right)=\left(X+\frac{B_{1}}{2}\right) \alpha_{B} \times \Delta \Theta_{B / T}
\end{aligned}
$$

Equations 4 and 17 for the contact with the housing and 5 and 18 for the contact with the bearing give:

$$
\begin{aligned}
& d\left(P_{1 S}, f_{1}\right)=\frac{\left(H_{1}-S_{1}\right)+\left(\frac{t_{1 S}}{2}+\frac{t_{3 h}}{2}+t_{5 h}\right)}{2}+\left(X+\frac{H_{1}}{2}\right) \alpha_{H} \times \Delta \Theta_{H / T} \\
& d\left(P_{2 S}, f_{2}\right)=\frac{\left(B_{1}-S_{2}\right)+\left(\frac{t_{2 S}}{2}+\frac{t_{3 b}}{2}+t_{5 b}\right)}{2}-\left(X-\frac{B_{1}}{2}\right) \alpha_{B} \times \Delta \Theta_{B / T}
\end{aligned}
$$

With 2, 3 and 6 the previous equations lead to: 


$$
\begin{aligned}
& Y_{\text {max }}^{T}=Y_{\text {max }}^{a}+K_{H} \times\left(X+\frac{H_{1}}{2}\right) \alpha_{H} \times \Delta \Theta_{H / T}-K_{B} \times\left(X-\frac{B_{1}}{2}\right) \alpha_{B} \times \Delta \Theta_{B / T} \\
& Y_{\text {min }}^{T}=Y_{\text {min }}^{a}+K_{H} \times\left(X+\frac{H_{1}}{2}\right) \alpha_{H} \times \Delta \Theta_{H / T}-K_{B} \times\left(X-\frac{B_{1}}{2}\right) \alpha_{B} \times \Delta \Theta_{B / T}
\end{aligned}
$$

Usable equations must be expressed grouping factors of each independent temperature. Each global factor can be a positive value or a negative value. In a second step, uncertainties of temperature are separated but with an absolute value for the factors.

In the case of this experimental mechanism, the rest of the study does not impact on the uncertainties. Thus, by taking into account equation 16 and Figure 5, equations 21 and 22 became:

$$
\begin{aligned}
& Y_{\max }^{T}=Y_{\max }^{a}+K_{H} \times\left(X+\frac{H_{1}}{2}\right) \alpha_{H}\left(\theta_{H / T}-\theta_{0}\right)-K_{B} \times\left(X-\frac{B_{1}}{2}\right) \alpha_{B}\left(\theta_{B / T}-\theta_{0}\right) \\
& +\left[\left|K_{H} \times\left(X+\frac{H_{1}}{2}\right)\right| \alpha_{H} \frac{\Delta \theta_{H / T}}{2}+\left|K_{B} \times\left(X-\frac{B_{1}}{2}\right)\right| \alpha_{B} \frac{\Delta \theta_{B / T}}{2}\right] \\
& Y_{\text {min }}^{T}=Y_{\min }^{a}+K_{H} \times\left(X+\frac{H_{1}}{2}\right) \alpha_{H}\left(\theta_{H / T}-\theta_{0}\right)-K_{B} \times\left(X-\frac{B_{1}}{2}\right) \alpha_{B}\left(\theta_{B / T}-\theta_{0}\right) \\
& +\left[\left|K_{H} \times\left(X+\frac{H_{1}}{2}\right)\right| \alpha_{H} \frac{\Delta \theta_{H / T}}{2}+\left|K_{B} \times\left(X-\frac{B_{1}}{2}\right)\right| \alpha_{B} \frac{\Delta \theta_{B / T}}{2}\right]
\end{aligned}
$$

Those equations could be rearranged as:

$$
\begin{aligned}
& Y_{\max }^{T}=Y_{\text {max }}^{a}+d^{\theta} Y^{T}+d^{\Delta \theta} Y^{T} \\
& Y_{\min }^{T}=Y_{\min }^{a}+d^{\theta} Y^{T}-d^{\Delta \theta} Y^{T}
\end{aligned}
$$

Where:

$\mathrm{Y}_{\max }{ }^{\mathrm{a}}$ is the influence of tolerancing at ambient temperature

$d^{\theta} Y^{T}$ is the deviation due to calculated temperature

$\mathrm{d}^{\Delta \theta} \mathrm{Y}^{\mathrm{T}}$ is the deviation due to uncertainties of temperature

\subsection{Respect of the requirement}

As it is said in chapter 3.1 , the requirement must be respected at every stage. While taking into account equations 25 and 26, the two equations of system 1 should be written:

$$
\left\{\begin{array}{l}
Y_{\max }^{T}=Y_{\max }^{a}+d^{\theta} Y^{T}+d^{\Delta \theta} Y^{T} \leq L_{F}+\frac{t_{P}}{2} \\
Y_{\text {min }}^{T}=Y_{\min }^{a}+d^{\theta} Y^{T}-d^{\Delta \theta} Y^{T} \geq L_{F}-\frac{t_{P}}{2}
\end{array}\right.
$$

Considering the temperature profile (Fig.5), $\mathrm{Y}$ is maximal for $\mathrm{T}=140 \mathrm{~s}$ and $\mathrm{Y}$ is minimal at $\mathrm{T}=0 \mathrm{~s}$ which corresponds to ambient temperature. 


$$
\left\{\begin{array}{l}
Y_{\max }=Y_{\max }^{a}+d^{\theta} Y^{140}+d^{\Delta \theta} Y^{140} \leq L_{F}+\frac{t_{P}}{2} \\
Y_{\min }=Y_{\min }^{a} \geq L_{F}-\frac{t_{P}}{2}
\end{array}\right.
$$

The sum and the difference of the two equations of the previous system give:

$$
\left\{\begin{array}{l}
X=L_{F}-\frac{\left(d^{\theta} Y^{140}+d^{\Delta \theta} Y^{140}\right)}{2} \\
t_{4 S}+K_{H} \times\left(H_{1}-S_{1}+\frac{t_{1 S}}{2}+\frac{t_{3 h}}{2}+t_{5 S}\right)+K_{B} \times\left(B_{1}-S_{2}+\frac{t_{2 S}}{2}+\frac{t_{3 b}}{2}+t_{5 b}\right)+ \\
d^{\theta} Y^{140}+d^{\Delta \theta} Y^{140}=t_{P}
\end{array}\right.
$$

The important point in this system is that $\mathrm{d}^{\theta} \mathrm{Y}^{140}$ and $\mathrm{d}^{\Delta \theta} \mathrm{Y}^{140}$ are dependent on $\mathrm{X}$. thus:

$$
\left\{\begin{array}{l}
X=\frac{2 L_{F}-\frac{H_{1}}{2} K_{H} \alpha_{H}\left[\left(\theta_{H / 140}-\theta_{0}\right)+\frac{\Delta \theta_{H / 140}}{2}\right]-\frac{B_{1}}{2} K_{B} \alpha_{B}\left[\left(\theta_{B / 140}-\theta_{0}\right)-\frac{\Delta \theta_{B / 140}}{2}\right]}{2+K_{H} \alpha_{H}\left[\left(\theta_{H / 140}-\theta_{0}\right)+\frac{\Delta \theta_{H / 140}}{2}\right]-K_{B} \alpha_{B}\left[\left(\theta_{B / 140}-\theta_{0}\right)-\frac{\Delta \theta_{B / 140}}{2}\right]} \\
t_{4 S}+K_{H} \times\left(H_{1}-S_{1}+\frac{t_{1 S}}{2}+\frac{t_{3 h}}{2}+t_{5 S}\right)+K_{B} \times\left(B_{1}-S_{2}+\frac{t_{2 S}}{2}+\frac{t_{3 b}}{2}+t_{5 b}\right)+ \\
d^{\theta} Y^{140}+d^{\Delta \theta} Y^{140}=t_{P}
\end{array}\right.
$$

The optimization of this system leads to find the best nominal values and tolerances for the mechanism by taking into account the thermal expansion and taking care of the fact that $\mathrm{d}^{\theta} \mathrm{Y}^{140}$ and $\mathrm{d}^{\Delta \theta} \mathrm{Y}^{140}$ depend on $\mathrm{X}$.

\section{Application on mechanism}

\subsection{Synthesis of tolerance}

This section depicts some results of the integration of effects of thermal variation onto the tolerancing in order to respect $\mathrm{L}_{\mathrm{F}}=50 \mathrm{~mm}$ and $\mathrm{t}_{4 \mathrm{~S}}=0.3 \mathrm{~mm}$ with $\mathrm{L}_{\mathrm{w}}=100 \mathrm{~mm}$ and $\mathrm{L}_{\mathrm{P}}=$ 40mm. $\alpha_{\mathrm{H}}=\alpha_{\mathrm{B}}=1.1710^{-5} \mathrm{~K}^{-1}$ which corresponds to steel material. The uncertainties estimated are more or less $15 \%$ of nominal temperature.

With the first model, the temperature is not taken into account. Previous equations lead to: 


$$
\left\{\begin{array}{l}
X=50 m m \\
t_{4 S}+K_{H} t_{5 h}+K_{B} t_{5 b}=t_{p}-K_{H}\left(H_{1}-S_{1}+\frac{t_{1 S}}{2}+\frac{t_{3 h}}{2}\right)-K_{B}\left(B_{1}-S_{2}+\frac{t_{2 S}}{2}+\frac{t_{3 b}}{2}\right)
\end{array}\right.
$$

To simplify the calculation, the tolerancing of the fittings between the shaft and the housing or the bearing are supposed to be a classical H7g6. So:
$\mathrm{H}_{1}=20.011 \mathrm{~mm}$
$\mathrm{B}_{1}=25.011 \mathrm{~mm}$
$\mathrm{S}_{1}=19.987 \mathrm{~mm}$
$\mathrm{S}_{2}=24.987 \mathrm{~mm}$
$\mathrm{t}_{1 \mathrm{~S}}=0.013 \mathrm{~mm}$
$\mathrm{t}_{2 \mathrm{~S}}=0.013 \mathrm{~mm}$
$\mathrm{t}_{1 \mathrm{~h}}=0.021 \mathrm{~mm}$
$\mathrm{t}_{1 \mathrm{~b}}=0.021 \mathrm{~mm}$

Thus, the calculation leads to find the values of $t_{4 s}, t_{5 h}$ and $t_{5 b}$.

Moreover, the repartition of tolerances is supposed equal for each influence. Thus:

$$
\left\{\begin{array}{l}
t_{4 S}=\frac{t_{P}-K_{H}\left(H_{1}-S_{1}+\frac{t_{1 S}}{2}+\frac{t_{3 h}}{2}\right)-K_{B}\left(B_{1}-S_{2}+\frac{t_{2 S}}{2}+\frac{t_{3 b}}{2}\right)}{3}=0.075 \mathrm{~mm} \\
K_{H} t_{5 h}=\frac{t_{P}-K_{H}\left(H_{1}-S_{1}+\frac{t_{1 S}}{2}+\frac{t_{3 h}}{2}\right)-K_{B}\left(B_{1}-S_{2}+\frac{t_{2 S}}{2}+\frac{t_{3 b}}{2}\right)}{3}=0.075 \mathrm{~mm} \\
K_{B} t_{5 b}=\frac{t_{P}-K_{H}\left(H_{1}-S_{1}+\frac{t_{1 S}}{2}+\frac{t_{3 h}}{2}\right)-K_{B}\left(B_{1}-S_{2}+\frac{t_{2 S}}{2}+\frac{t_{3 b}}{2}\right)}{3}=0.075 \mathrm{~mm}
\end{array}\right.
$$

The results of those calculations are represented into the first column of the table 1.

With the second model, thermal dilatations are taken into account for the determination of tolerances. Temperature uncertainties are supposed zero. The unknown values are determined in the same way than for the model 1 but considering equation 30 with the relationship to optimize X. Those elements are represented into the second column of the table 1 .

With the third model, thermal dilatations and temperature uncertainties are taken into account for the calculation which is proceeded as for model 2 . Those elements are represented into the second column of the table 1 .

The calculations of $\mathrm{Y}_{\max }{ }^{\mathrm{T}}$ and $\mathrm{Y}_{\min }{ }^{\mathrm{T}}$ for each case are done in the same way. Those calculations take into account the dimensions and tolerances previously calculated, a temperature variation and uncertainties on temperature. 


\begin{tabular}{|c|c|c|c|c|c|c|c|c|}
\hline \multicolumn{9}{|c|}{$\mathrm{L}_{\mathrm{F}}=50 \mathrm{~mm}$} \\
\hline \multicolumn{9}{|c|}{$t_{p}=0.3 \mathrm{~mm}$} \\
\hline \multicolumn{9}{|c|}{$\mathrm{L}_{\mathrm{w}}=100 \mathrm{~mm}$} \\
\hline \multicolumn{9}{|c|}{$\mathrm{L}_{\mathrm{P}}=\mathbf{4 0 \mathrm { mm }}$} \\
\hline \multicolumn{3}{|c|}{$\begin{array}{l}\text { Model } 1 \\
\text { Without thermal consideration }\end{array}$} & \multicolumn{3}{|c|}{$\begin{array}{c}\text { Model } 2 \\
\text { With nominal temperature }\end{array}$} & \multicolumn{3}{|c|}{$\begin{array}{c}\text { Model } 3 \\
\text { With uncertainties on temperature }\end{array}$} \\
\hline $\mathrm{t}_{4 \mathrm{~s}}$ & 0.075 & $\mathrm{~mm}$ & $t_{4 s^{*}}$ & 0.046 & $\mathrm{~mm}$ & $\mathrm{t}_{4 \mathrm{~s}^{\prime}}$ & 0.040 & $\mathrm{~mm}$ \\
\hline Xh & 50.000 & $\mathrm{~mm}$ & $\mathbf{X h}^{*}$ & 49.955 & $\mathrm{~mm}$ & $\mathbf{X h '}$ & 49.947 & $\mathrm{~mm}$ \\
\hline $\mathbf{t}_{5 \mathrm{~h}}$ & 0.054 & $\mathrm{~mm}$ & $t_{5 h}{ }^{*}$ & 0.033 & $\mathrm{~mm}$ & $t_{5 h^{\prime}}$ & 0.029 & $\mathrm{~mm}$ \\
\hline $\mathrm{Xb}$ & 50.000 & $\mathrm{~mm}$ & $\mathbf{X b}^{*}$ & 49.955 & $\mathrm{~mm}$ & $\mathrm{Xb}$ & 49.947 & $\mathrm{~mm}$ \\
\hline$t_{5 b}$ & 0.188 & $\mathrm{~mm}$ & $\mathrm{t}_{5 \mathrm{~b}}{ }^{*}$ & 0.114 & $\mathrm{~mm}$ & $t_{5 b}$ & 0.101 & $\mathrm{~mm}$ \\
\hline$Y_{\max }$ & 50.257 & $\mathrm{~mm}$ & $Y_{\max }{ }^{*}$ & 50.163 & $\mathrm{~mm}$ & $Y_{\max }{ }^{\prime}$ & 50.150 & $\mathrm{~mm}$ \\
\hline$Y_{\min }$ & 49.850 & $\mathrm{~mm}$ & $Y_{\min }{ }^{*}$ & 49.850 & $\mathrm{~mm}$ & $Y_{\min }{ }^{\prime}$ & 49.850 & $\mathrm{~mm}$ \\
\hline
\end{tabular}

Table 1: Parameters of the demonstrator mechanism

Table 1 shows that if temperature variations are taken into account into tolerancing, the tolerances decrease but for model 1 and $2, \mathrm{Y}_{\max }$ requirement is not respected.

\subsection{Behavior of the mechanism}

These values are now included in equations (23) and (24) to determine the behavior of the mechanism.

The resultants of calculations are shown below. The underlined values are $Y_{\max }$ and $Y_{\min }$ for each model.

\begin{tabular}{|c|c|c|c|c|c|c|c|c|c|}
\hline & Time & 0 & 20 & 40 & 60 & 80 & 100 & 120 & 140 \\
\hline & $\theta \mathrm{H}-\theta \mathrm{O}$ & 0 & 28.5 & 53.5 & 78 & 95 & 100 & 100 & 100 \\
\hline & $\theta \mathrm{B}-\theta \mathrm{O}$ & 0 & 12 & 25.25 & 37.5 & 46 & 50 & 50 & 50 \\
\hline & $\Delta \theta H / 2$ & 0 & 4.275 & 8.025 & 11.7 & 14.25 & 15 & 15 & 15 \\
\hline & $\Delta \theta \mathrm{B} / 2$ & 0 & 1.8 & 3.7875 & 5.625 & 6.9 & 7.5 & 7.5 & 7.5 \\
\hline \multirow{2}{*}{ Model 1} & $Y \max T$ & 50.150 & 50.181 & 50.207 & 50.234 & 50.252 & 50.257 & 50.257 & 50.257 \\
\hline & $Y \min T$ & $\underline{49.850}$ & 49.871 & 49.889 & 49.907 & 49.919 & 49.922 & 49.922 & 49.922 \\
\hline \multirow{2}{*}{ Model 2} & $Y \max T^{\star}$ & 50.061 & 50.090 & 50.116 & 50.141 & 50.159 & 50.163 & 50.163 & 50.163 \\
\hline & $Y \min T^{*}$ & $\underline{49.850}$ & 49.872 & 49.891 & 49.910 & 49.922 & 49.926 & 49.926 & 49.926 \\
\hline \multirow{2}{*}{ Model 3} & $Y \max T$ & 50.045 & 50.075 & 50.101 & 50.127 & 50.145 & 50.150 & 50.150 & 50.150 \\
\hline & $Y \min T$ & $\underline{49.850}$ & 49.871 & 49.890 & 49.908 & 49.920 & 49.923 & 49.923 & 49.923 \\
\hline
\end{tabular}

Table 2: Displacement values 


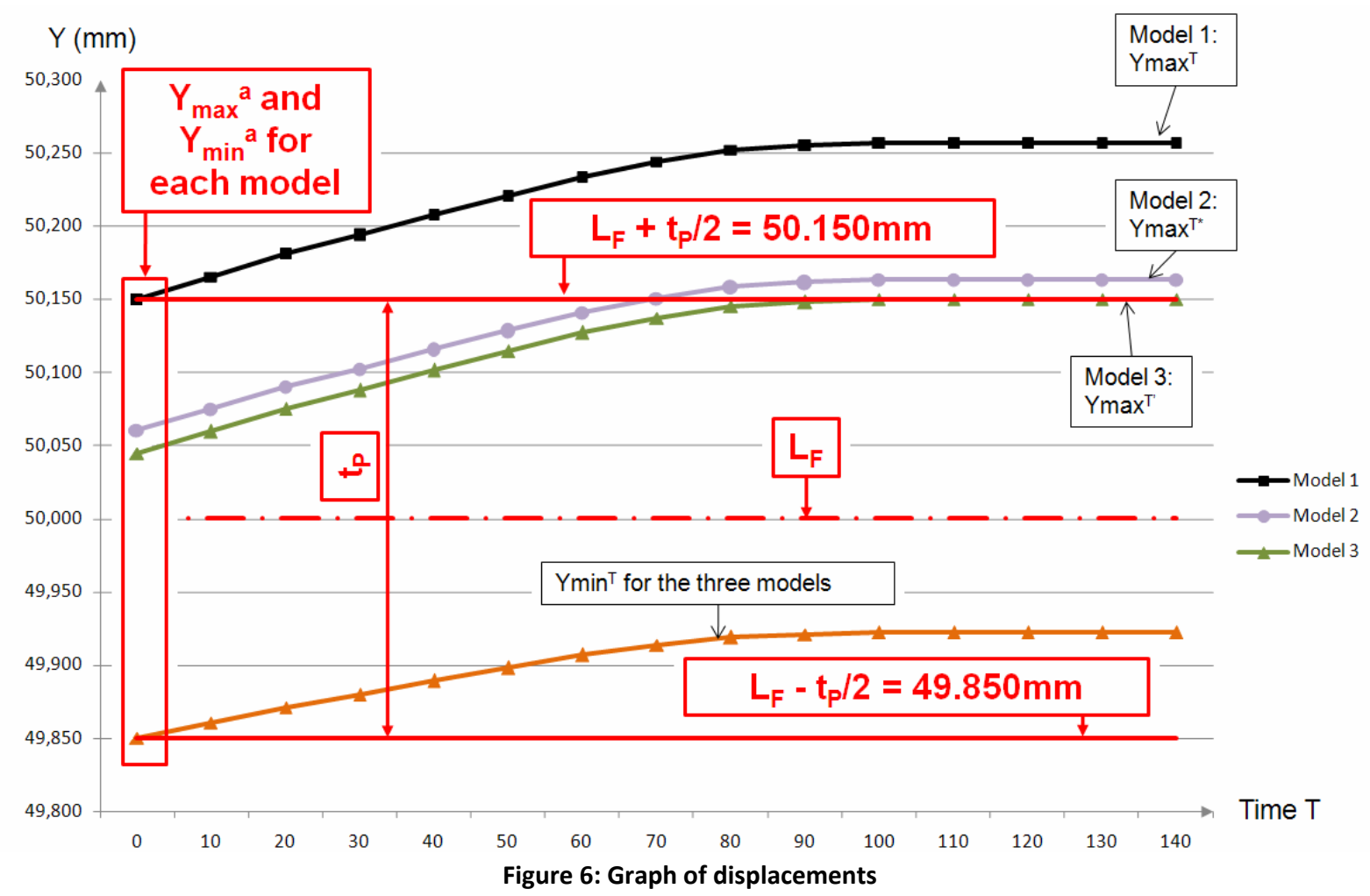

Table 2 and Figure 6 show that for this particular temperature profiles the displacement $Y_{\text {min }}$ of $\mathrm{P}$ in $-\mathbf{f}$ direction is quite identical for each case and always respects the requirement.

But in $\mathbf{f}$ direction, the model has a significant impact. To respect the requirement, it is necessary to take into account temperature and uncertainties on temperature effects. This case respects the requirement but has the smaller tolerances.

The model 1 is not acceptable. The overstepping corresponds to $30 \%$ of the tolerance requirement.

For model 2, the overstepping of $\mathrm{Y}_{\max }$ requirement is $0.013 \mathrm{~mm}$. In comparison, the tolerance g6 of the shaft is $0.013 \mathrm{~mm}$.

The model 3 is fully in the requirement.

In conclusion, it is necessary to take into account the thermal effect. The influence of the uncertainties on temperature is small but with the same order as classical tolerances.

\subsection{Gradient of temperature in parts}

For industrial problems, the calculations are usually done with CAD system and finite elements method and use nominal dimensions. One of the results of this is a displacement of each node of the mesh.

To integrate results obtained with finite element onto tolerancing, it is sufficient to get the displacements of specific points, for example in points $\mathrm{P}_{h}$ and $\mathrm{P}_{b}$ (Fig.4). The exports of the calculations give those displacements. If there is a node on every wanted point, the displacements of those nodes give the thermal influences at point P. Otherwise the nearest 
points from the position of wanted points should be studied.

The displacements $d^{\theta}\left(P_{1 S}, f_{1}\right)$ and $d^{\theta}\left(P_{2 S}, f_{2}\right)$ obtained with the finite elements should be input into a adapted form of equations 21 and 22:

$$
\begin{aligned}
& Y_{\max }^{T}=Y_{\text {max }}^{a}+K_{H} \times d^{\theta}\left(P_{1 S}, f_{1}\right)-K_{B} \times d^{\theta}\left(P_{2 S}, f_{2}\right) \\
& Y_{\text {min }}^{T}=Y_{\text {min }}^{a}+K_{H} \times d^{\theta}\left(P_{1 S}, f_{1}\right)-K_{B} \times d^{\theta}\left(P_{2 S}, f_{2}\right)
\end{aligned}
$$

The uncertainties onto temperature should be estimated as uncertainties onto the displacements of the significant points.

If the temperature is not uniform into the parts, it is sufficient to know the displacement of points $\mathrm{P}_{\mathrm{h}}$ and $\mathrm{P}_{\mathrm{b}}$. If the contact between parts changes, it means that the displacement of the new contact point is smaller than the displacement of $\mathrm{P}_{h}$ or $\mathrm{P}_{\mathrm{b}}$. Thus, the calculation process with points $\mathrm{Ph}$ and $\mathrm{Pb}$ is more pessimistic and so the calculation is acceptable.

\section{Conclusion and future prospects}

This study shows that it is possible to link deformations due to the temperature variation with the tolerance synthesis in simple cases. Moreover, the impact of temperature variation onto deviation can be greater or on the same order than geometric defaults. Thus, the importance of taking into account both the geometric defaults and the thermal expansion into tolerance synthesis is demonstrated.

With the displacements of specific nodes of the mesh, it is possible to integrate thermal finite elements calculation with tolerancing. This point needs to be more investigated to be validated for complex mechanisms.

Thermal meshing model could be very fine by taking into account thin film of air between parts for example. But usually, thermal models do not take into account effects of tolerances or eccentricity due to clearance. The purpose of future prospects is to link thermal models with geometric models with defaults in order to find worst cases in realistic problematic.

This study opens another search possibility about the introduction of displacements due to stress into the calculations of the specification chains. Effectively, if the stresses into the mechanism are also calculated with finite elements, it allows taking the result into account with a nearby procedure.

This work will be now tested on real mechanisms of companies of QUICK_GPS project.

Acknowledgment: This work is financed by "Pôle de Compétitivité System@tic" and Région Ile de France in QUICK GPS project.

\section{References}


[1] B. Anselmetti, H. Louati. Generation of manufacturing tolerancing with iso standards. International Journal of Machine Tools and Manufacture, 45(10):1124 - 1131, 2005.

[2] V.J. Skowronski, J.U. Turner. Using monte-carlo variance reduction in statistical tolerance synthesis. Computer-Aided Design, 29(1):63 - 69, 1997.

[3] S.D. Nigam, J.U. Turner. Review of statistical approaches to tolerance analysis. Computer-Aided Design, 27(1):6 - 15, 1995.

[4] A. Ballu, L. Mathieu. Choice of functional specifications using graphs within the framework of education, In CIRP Seminar on CAT, pages 197 - 206, 1999. Enschede, The Netherlands.

[5] K.W. Chase, J. Gao, S.P. Magleby, C.D. Sorensen. Including geometric feature variations in tolerance analysis of mechanical assemblies. IIE Transactions, 28:795 $807,1996$.

[6] B. Anselmetti. Calcul tridimensionnel de la résultante des chaînes de cotes en cotation iso. Mécanique \& Industries, 8:173 - 185, 2007.

[7] B. Anselmetti. Cotation fonctionnelle tridimensionnelle et statistique. HERMES, 2008.

[8] B. Anselmetti. Part optimization and tolerances synthesis. Int J Adv Manuf Technol, DOI: $10.1007 / \mathrm{s} 00170-009-2355-6.2009$.

[9] G. Cid, F. Thiébaut, P. Bourdet. Taking the deformation into account for components' tolerancing., Proceeding IDMME 2004, Bath, UK.

[10] J. Stuppy, H. Meerkamm. Tolerance analysis of a crank mechanism by taking into account different kinds of deviation. In CIRP Cat conference, Annecy, France, 2009.

[11] R. Ramesh, M. A. Mannan, A. N. Poo. Error compensation in machine tools - a review: Part II : thermal errors. International Journal of Machine Tools and Manufacture, 40(9):1257 - 1284, 2000.

[12] L. Pierre, D. Teissandier, J.P. Nadeau. Analyse des tolérances géométriques dans un contexte multi-expertises, application à une turbine de moteur d'hélicoptère. In 18ème congrès Français de Mécanique, Grenoble, France, 2007. 